\title{
Coblation-assisted excision of hypopharyngeal venous malformation: a case report
}

\author{
Amit Kumar ${ }^{1,2}$, Anand Subash ${ }^{1,3^{*}}$ (D), Abhijeet Singh ${ }^{1,4}$, Sourabha Patro ${ }^{1}$ and Jaimanti Bakshi ${ }^{1}$
}

\begin{abstract}
Background: Adult hypopharyngeal venous malformations are rare. Unlike hemangiomas, venous malformations require surgical excision wherever feasible. We describe the case of a hypopharyngeal venous malformation and use of coblation to achieve complete excision.

Case presentation: A 28-year-old male presented to the emergency department with sudden-onset hematemesis, and melena for 3 days. Examination revealed a broad-based reddish polypoidal lesion (mulberry like) arising from the left aryepiglottic fold and medial wall of the pyriform sinus. Contrast-enhanced magnetic resonance scan and angiogram of the neck was done, which revealed an intensely enhancing vascular lesion. He underwent a selective embolization of the feeder vessels achieving $80 \%$ reduction in the post run blush. We excised the lesion in toto using coblation considering its superior hemostatic control and maneuverability.

Conclusion: The use of coblation is a relatively safe and easy technique to learn and perform in management of vascular tumor of hypopharynx and upper airway. When appropriately performed, it provides a bloodless field and causes minimal damage to surrounding tissue. However, knowledge of external approaches is mandatory for management of complications.
\end{abstract}

Keywords: Hypopharynx, Venous malformation, Coblation, Larynx

\section{Background}

In 1924, Hayden described the first case of adult laryngeal venous malformation. Adult hypopharyngeal venous malformations are rare [1]. In contrast to hemangiomas, which can resolve spontaneously, the adult venous malformation requires complete surgical excision. We describe our experience in the management of a case of hypopharyngeal venous malformation in a young adult. He presented to us with hematemesis and after evaluation underwent a selective embolization and transoral excision of the lesion. We used coblation to excise the

\footnotetext{
* Correspondence: dranandsubash@gmail.com

'Department of Otolaryngology-Head and Neck Surgery, PGIMER, 5th Floor,

B Block, Nehru Hospital, PGIMER, Chandigarh, India

${ }^{3}$ Department of Head and Neck Surgical Oncology, HCG Cancer Centre,

Bangalore, India

Full list of author information is available at the end of the article
}

lesion and its use for venous malformation has not been explored earlier.

\section{Case presentation}

A 28-year-old male presented to the emergency department with sudden-onset hematemesis, and melena for 3 days. He underwent an upper gastrointestinal endoscopy, and it revealed a reddish polypoidal lesion in the left pyriform fossa. The rest of the upper gastrointestinal tract did not show any bleeders. He underwent a fiberoptic nasopharyngoscopy. The examination revealed a broad-based reddish polypoidal lesion (mulberry like) arising from the left aryepiglottic fold and medial wall of the pyriform sinus (Fig. 1). Contrast-enhanced magnetic resonance scan and angiogram of the neck was done, which revealed an intensely enhancing vascular lesion in the area of left pyriform fossa and hypopharynx

\section{Springer Open}

(ㅇ The Author(s). 2021 Open Access This article is licensed under a Creative Commons Attribution 4.0 International License, which permits use, sharing, adaptation, distribution and reproduction in any medium or format, as long as you give appropriate credit to the original author(s) and the source, provide a link to the Creative Commons licence, and indicate if changes were made. The images or other third party material in this article are included in the article's Creative Commons licence, unless indicated otherwise in a credit line to the material. If material is not included in the article's Creative Commons licence and your intended use is not permitted by statutory regulation or exceeds the permitted use, you will need to obtain permission directly from the copyright holder. To view a copy of this licence, visit http://creativecommons.org/licenses/by/4.0/. 


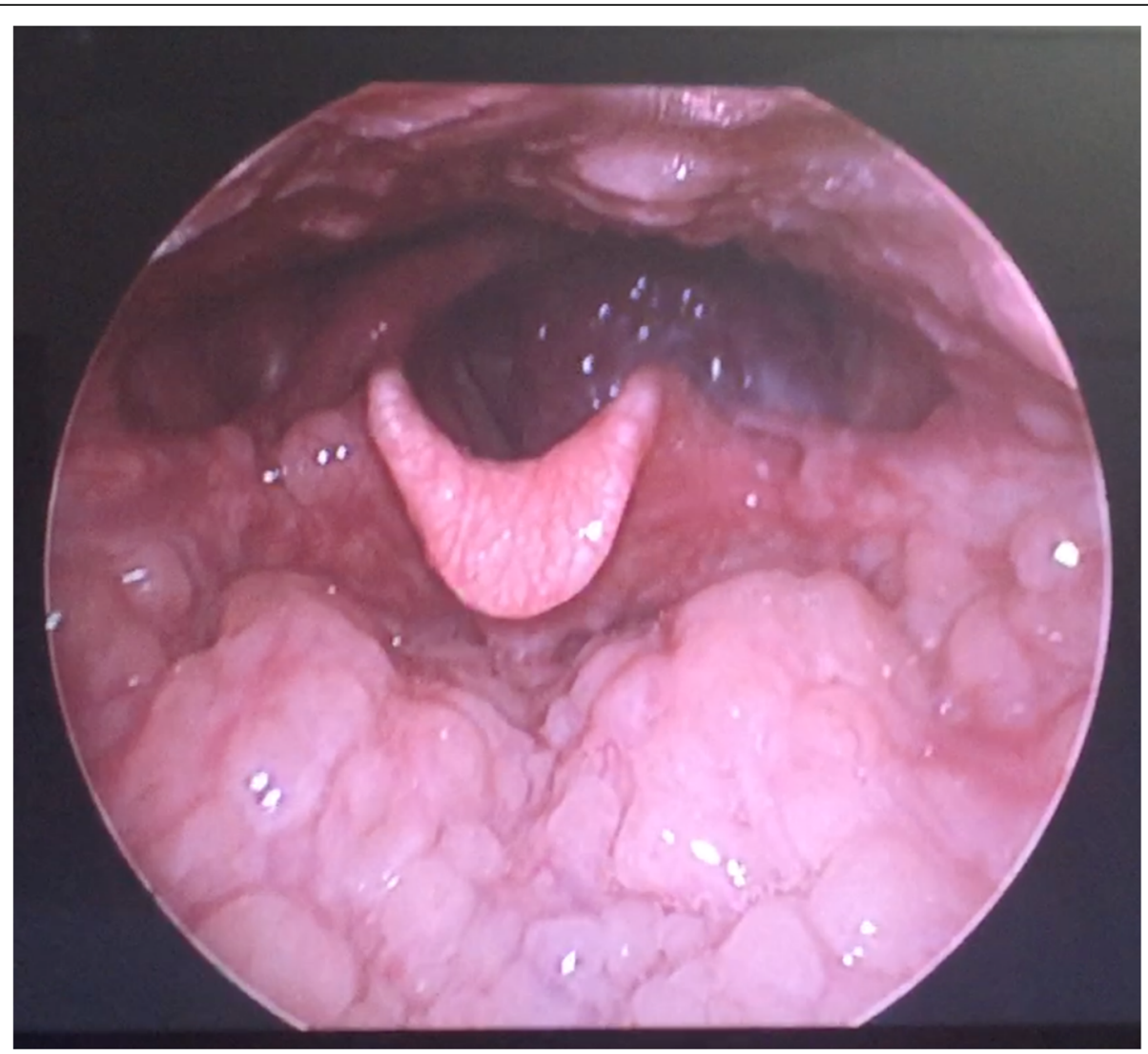

Fig. 1 Fiberoptic nasopharyngoscopy showing a mulberry-like lesion on the left pyriform fossa

with dominant feeders from the left superior thyroid artery (Figs. 2, 3). The patient was planned and underwent a selective embolization of the feeder vessels. There was approximately $80 \%$ reduction in the post run blush. The patient was scheduled for the surgery the next day. After induction, we performed a meticulous rigid direct laryngoscopic examination, keeping in mind the risk of a traumatic bleed. The lesion was seen involving the medial wall of the left pyriform sinus and extending anteriorly with minimal extension to the lateral wall of pyriform sinus. Our instituiton is a large volume center and is also equipped with a Lumenis $\mathrm{CO} 2$ laser system. Considering its superior hemostatic control and the malleability of micro-laryngeal wand, coblation was our preferred choice. We used the Smith and Nephew ${ }^{\bullet}$ microlaryngeal coblation wand, with coagulation setting at

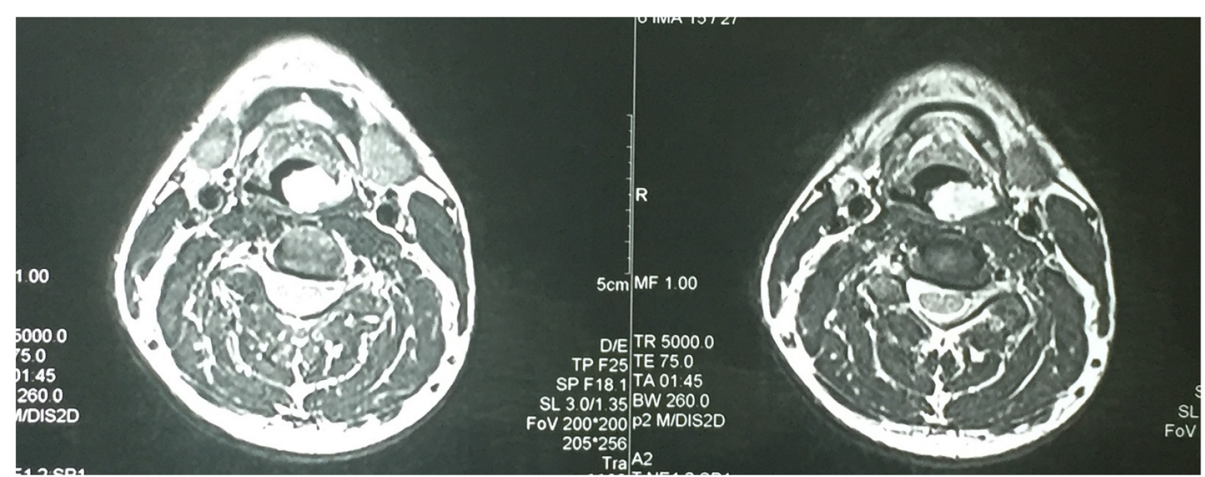

Fig. 2 MRI showing an intensely enhancing lesion in the left hypopharynx 


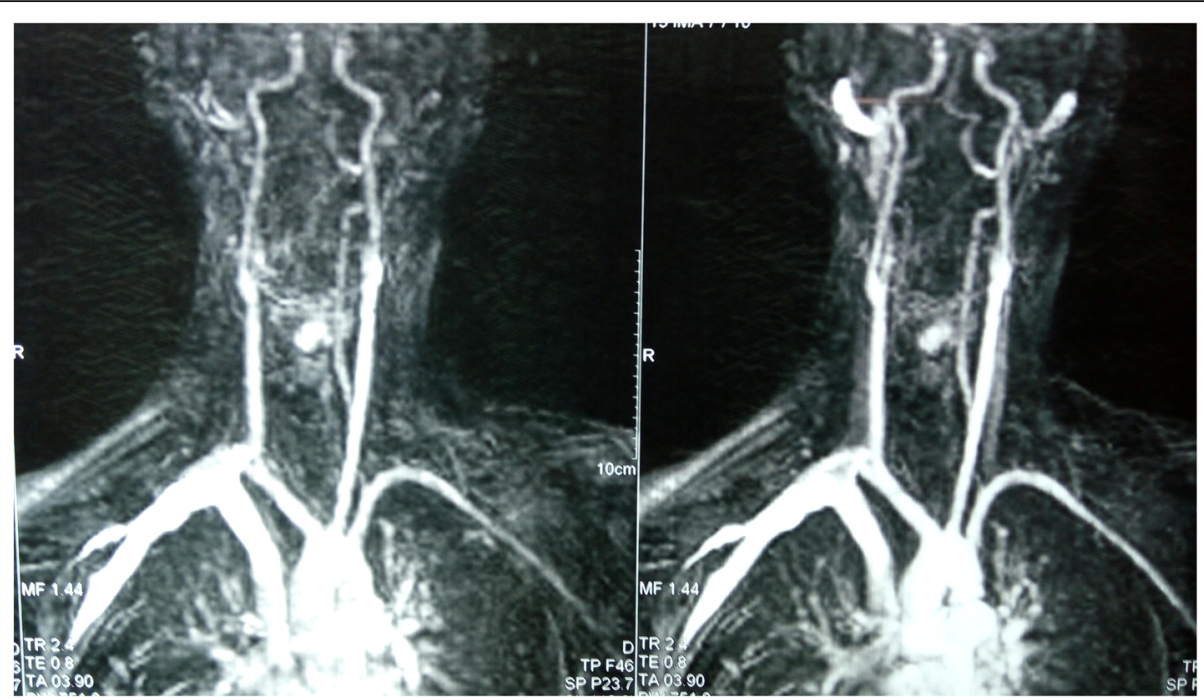

Fig. $3 \mathrm{MR}$ angiography showing dominant feeders from the superior thyroid artery

three and coblation at 7 . We excised the lesion with a rim of adjoining mucosa preserving the arytenoid.

The patient made an uneventful recovery and was decannulated successfully on postoperative day five. Postoperative histopathology was suggestive of cavernous venous malformation (Fig. 4). At 3-month followup, the patient was asymptomatic and had a normal voice and swallowing function.

\section{Discussion}

Vascular malformation in head and neck comprises 14$65 \%$ of all the vascular lesions in the body [2]. The most common site in the head and neck is the oral cavity. Mulliken and Glowacki classified vascular lesions into two main categories, venous malformations and vascular malformations. In 1996, the International Society for the study of vascular anomalies (ISSAVA) classified vascular

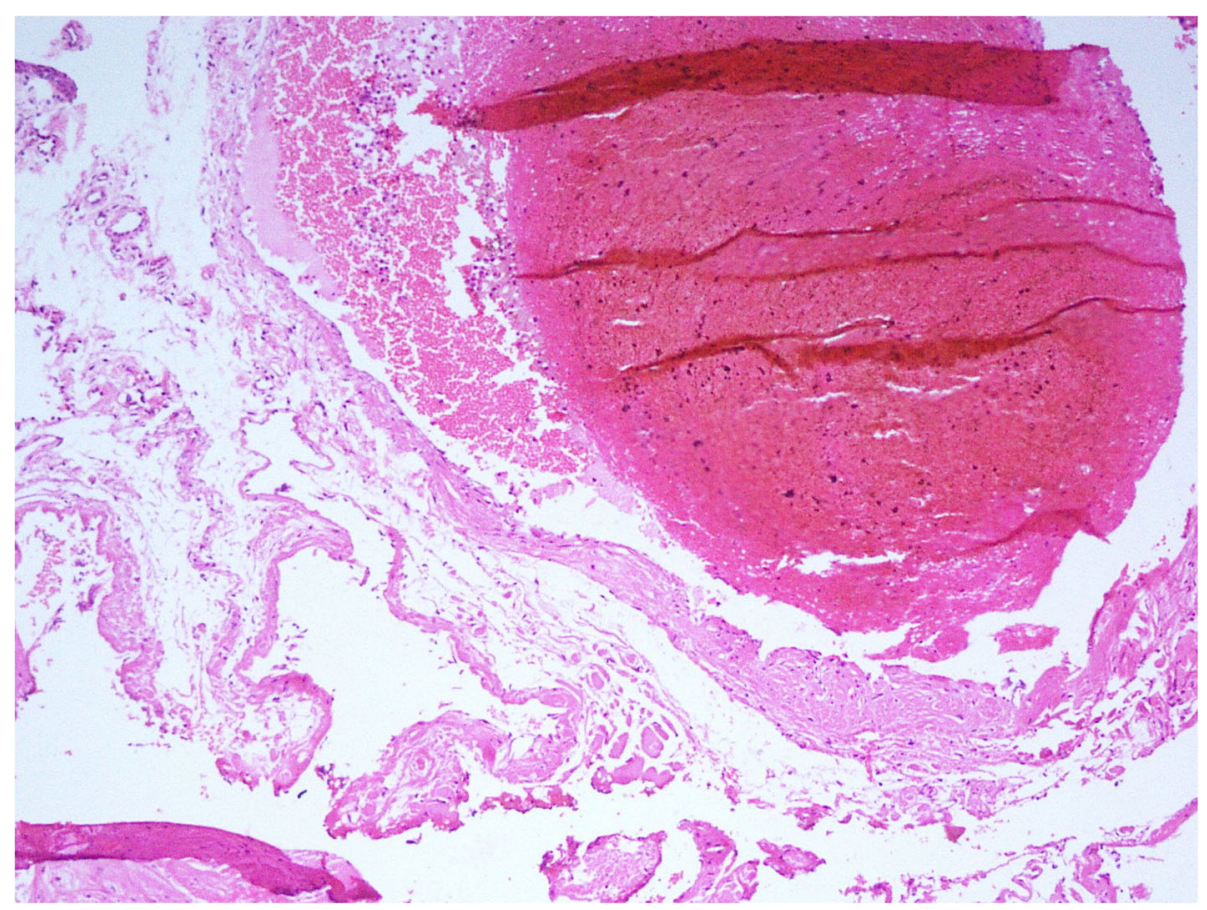

Fig. 4 Digital images of the slides confirming the diagnosis of cavernous venous malformation 
lesions into vascular tumors and vascular malformations [3]. Venous malformations are classified as cavernous and capillary type depending upon the diameter of the vessels. A cavernous type is the most common type in the laryngopharyngeal area [4].

Angiography is reserved for confirming a doubtful diagnosis when surgery or embolization is planned. It demonstrates flow characteristics, feeding and draining vessels, and dangerous anastomoses. Surgical ligation of proximal feeders is not recommended as it accentuates the formation of collaterals and precludes the option of embolization. Embolization pre-operatively decreases intraoperative blood loss and allows easier surgical resection. Total resection is necessary for the cure, as chances of recurrences are high with incomplete resections [5].

Adult hypopharyngeal venous malformations are rare and recommend treatment involved complete surgical removal. For large lesions with extra laryngeal spread, a transcervical approach with laryngo-fissure has been described. Smaller lesions without extra-laryngeal spread can be managed effectively with laser, with an effectiveness of 77 to 100\% [3]. Surgical resection of large pharyngolaryngeal venous malformation has been described in the literature using ethylene-vinyl alcohol copolymer (Onyx) embolization ultrasonic system [6]. Coblation is a minimally invasive, low thermal technology for the effective dissection and removal of the tissues.

Controlled ablation (coblation) is a bipolar plasma device designed to operate at a relatively low temperature and gently dissolve and shrink the tissue. The thermal damage to surrounding healthy tissue this way is minimized. Coblation not only ablates but also coagulates the blood vessels. Lasers are perfect for making incisions; they are poorer for hemostasis and raise concerns about intraoperative bleeding [7]. It is an alternative. However, it is costly, increases scarring and damage to adjacent tissue. With laser, there is always a risk of airway fire. Other limitations of laser include special endotracheal tubes, negotiation of the lasing beam, mucosal burns, and stenosis $[8,9]$.

In our case, we used The PRECISE LW laryngeal wand. It has a working length of $16.5 \mathrm{~cm}$ with a 45degree angulation at the shaft and 15-degree angulation at tip offering optimal ergonomics for a laryngeal procedure. The wand is malleable, which helps the surgeon bend the wand for optimal use. With coblation, we could control bleeding better. Also, the damage to the surrounding tissue was minimized.

Squamous cell carcinoma of the hypopharynx can also present with a polypoidal lesion, and histopathological examination is a must to rule out the underlying malignancy. In our case, the final histopathological examination showed an irregular venous-type channel, lined by flat endothelial cells and scant smooth muscle and was suggestive of venous malformation. Histological differential diagnosis should include hemangiopericytoma (potentially malignant lesion) and angiosarcoma (synonymous with malignant hemangioendothelioma) [5].

\section{Conclusion}

The use of coblation is a relatively safe and secure technique to learn and perform in management of vascular tumor of the hypopharynx and upper airway. When appropriately performed, it provides a bloodless field and causes minimal damage to surrounding tissue. However, knowledge of external approaches is mandatory for the management of complications.

\section{Acknowledgements \\ None}

Authors' contributions

The authors read and approved the final manuscript. Manuscript preparation: AK, AS, AbS, and SP. Manuscript revision: AS, AbS, SP, and JB. Concept and design: JB and AK.

Funding

No funding

Availability of data and materials

Available

\section{Declarations}

Ethics approval and consent to participate

Not applicable

Consent for publication

Written informed consent for publication of his clinical details and/or clinical images was obtained from the patient.

Competing interests

No conflict of interest

\section{Author details}

${ }^{1}$ Department of Otolaryngology-Head and Neck Surgery, PGIMER, 5th Floor, B Block, Nehru Hospital, PGIMER, Chandigarh, India. ${ }^{2}$ Department of Otolaryngology-Head and Neck Surgery, AlIMS, Rishikesh, India. ${ }^{3}$ Department of Head and Neck Surgical Oncology, HCG Cancer Centre, Bangalore, India. ${ }^{4}$ Department of Surgical Oncology, AllMS, Rishikesh, India.

Received: 7 April 2021 Accepted: 19 May 2021

Published online: 05 June 2021

References

1. Guo YC, Chu PY, Ho DM, Chang SY (2001) Hemangioma of the pyriform sinus. Otolaryngol Head Neck Surg. 124(6):707-708. https://doi.org/10.1177/ 019459980112400627

2. Kobayashi K, Nakao K, Kishishita S, Tamaruya N, Monobe H, Saito K, Kihara A (2013) Vascular malformations of the head and neck. Auris Nasus Larynx. 40(1):89-92. https://doi.org/10.1016/j.anl.2012.02.002

3. Zheng JW, Zhou Q, Yang XJ, Wang YA, Fan XD, Zhou GY, Zhang ZY, Suen JY (2010) Treatment guideline for hemangiomas and vascular malformations of the head and neck. Head Neck. 32(8):1088-1098. https:// doi.org/10.1002/hed.21274

4. Lucioni M, Marioni G, Della Libera D, Rizzotto G (2006) Adult laryngeal hemangioma $\mathrm{CO} 2$ laser excision. A single institution 3-year experience (Vittorio Veneto 2001-2003). Acta Otolaryngol. 126(6):621-626. https://doi. org/10.1080/00016480500452517

5. Panda NK, Reddy CE, Sharma RK, Bapuraj JR, Radotra BD (2002) High flow vascular malformations: review of literature and a case report. Indian J Otolaryngol Head Neck Surg. 54(3):225-228. https://doi.org/10.1007/BF02 993109 
6. Valls-Mateus M, Román LS, Macho J, Nadal A, Bernal-Sprekelsen M, Vilaseca I (2017) Transoral ultrasonic surgery of pharyngolaryngeal giant hemangioma after ethylene-vinyl alcohol copolymer (Onyx) embolization. Head Neck 39(6):1239

7. Kamijo A, Hatsushika K, Kanemaru S, Moriyama M, Kase Y, Masuyama K (2013) Five adult laryngeal venous malformation cases treated effectively with sclerotherapy. Laryngoscope. 123(11):2766-2769. https://doi.org/10.1 002/lary.24095

8. Deenadayal D, Naeem N, Bommakanti V (2018) Coblation: an alternative to CO2 laser and microdebrider for laryngeal papillomatosis. Int J Otolaryngol Head Neck Surgery 7:47-54. https://doi.org/10.4236/ijohns.2018.72007

9. Chouhan, A., Kulhari, M., Amisha, B. and Kasliwal, N. (2016) Microscopic surgery with coblation for the treatment of benign laryngeal lesions: a case report. Int J Otolaryngol Head \& Neck Surgery, 5, 125-128. http://dx.doi.org/ https://doi.org/10.4236/ijohns.2016.53021

\section{Publisher's Note}

Springer Nature remains neutral with regard to jurisdictional claims in published maps and institutional affiliations.

\section{Submit your manuscript to a SpringerOpen ${ }^{\circ}$ journal and benefit from:}

- Convenient online submission

- Rigorous peer review

- Open access: articles freely available online

- High visibility within the field

- Retaining the copyright to your article

Submit your next manuscript at $\boldsymbol{\nabla}$ springeropen.com 